\title{
AVALIAÇÃO DA QUALIDADE DA ÁGUA DE UMA MICROBACIA HIDROGRÁFICA NO MUNICÍPIO DE ILHA SOLTEIRA (SP)
}

\section{WATER QUALITY EVALUATION OF A HIDROGRAFIC MICRO BASIN IN THE ILHA SOLTEIRA CITY (SP)}

\section{Cristiano Poleto ${ }^{1}$, Sérgio Luis de Carvalho ${ }^{2}$, Tsunao Matsumoto $^{3}$}
${ }^{1,2,3}$ UNESP / FEIS-PPGEC, Ilha Solteira, SP, email: cristiano_poleto@hotmail.com; sergicar@bio.feis.unesp.br; tsunao@dec.feis.unesp.br

\section{RESUMO}

O presente trabalho teve como objetivo monitorar e avaliar a qualidade da água na microbacia hidrográfica do Córrego do Ipê, Município de Ilha Solteira, Estado de São Paulo, e o seu estado de degradação associado à utilização da área de entorno. Para isto, quinzenalmente, no período de março a dezembro de 2002, foram coletadas amostras de água em três pontos da microbacia hidrográfica e realizadas determinações de alguns parâmetros físico-químicos e biológicos que permitiram o cálculo do IQA. Mensalmente foram feitas análises da vazão $\mathrm{em} \mathrm{m}^{3} / \mathrm{s}$. Os resultados dos valores de IQA associados com observações feitas in loco, permitiram avaliar a qualidade da água e confirmar o atual estado de degradação desta bacia hidrográfica, manifestada pela inexistência de mata ciliar, assoreamento, elevação dos teores de elementos fertilizantes (fósforo e nitrogênio) e aumento dos níveis de concentrações de coliformes fecais e totais em alguns pontos analisados. Observou-se que a poluição do Córrego do Ipê manteve-se alta em escala temporal e espacial, levando-o a valores inferiores aos de um rio de Classe 2, com destaque para o Ponto "B", situado no meio urbano com qualidade da água variando de ruim a péssima. Isto requer medidas urgentes de correção e mitigação nos locais mais afetados e um manejo sustentável que permita a conservação de toda a microbacia estudada.

Palavras-chave: Microbacia. IQA. Degradação. Parâmetros físico-químicos e biológicos. 


\section{ABSTRACT}

This paper has the object monitoring and analyzing the water quality of the Córrego do Ipê Micro Basin, in Ilha Solteira City, São Paulo State, and its degradation stage in association to the utilization of the surrounding area. Thus, once every fifteen days, in the period between March and December of 2002, water samples were collected at three points of this micro basin and some of its physical, chemical and biological parameters were analyzed that allowed to calculate the WQI - Water Quality Indices. In addition, a monthly analysis of the flow was made. The WQI results, jointly to observations in loco, also made possible to evaluate the water quality and check the actual degradation stage of this micro basin that could be noticed by the non-existent ciliary vegetation. It was shown that the pollution in Córrego do Ipê was kept in high level in terms of time and space so its numbers are lower than a Class II level river, especially at Point "B", located at the urban environment, where the water quality alternates between bad and very bad, which require to take steps for urgent corrections and mitigation at the places that have been more affected and also a sustainable management, which would make possible the conservation of the entire micro basin in analysis.

Keywords: Micro basin. WQI. Degradation, Physical. Chemical and biological parameters.

\section{INTRODUÇÃO}

Ultimamente o uso dos recursos naturais disponíveis no mundo aumentou com as atividades antrópicas e seus diversos modos de utilização, principalmente em relação aos recursos hídricos das bacias hidrográficas (TUNDISI, 2003).

Os ecossistemas aquáticos acabam de uma forma ou de outra, servindo como reservatórios temporários ou finais de grande variedade e quantidade de poluentes descartados no ar, no solo ou diretamente nos corpos de água. Desta forma, a poluição do ambiente aquático, provocada pelo homem, de uma forma direta ou indireta, mediante a introdução de substâncias inorgânicas ou orgânicas, produz efeitos deletérios tais como: prejuízo aos seres vivos; perigo à saúde humana; efeitos negativos as atividades aquáticas (pesca, lazer, entre outras) e prejuízo à qualidade da água com respeito ao uso na agricultura, indústria e outras atividades econômicas (MEYBECK e HELMER, 1992).

O custo do tratamento de água para abastecimento público e a recuperação de lagos, rios e represas são elevados, o que ressalta a importância da preservação e cuidados sobre as formas de utilização, tanto da própria água como também dos recursos naturais como um todo (TUNDISI, 2003). A displicência e o descaso pela água e conseqüentemente o mau uso dos recursos naturais são problemas que devem ser resolvidos (POLETO, 2003). 
A ocupação desordenada dos municípios de Ilha Solteira, Suzanápolis e Pereira Barreto contribuiu para a degradação dos solos com conseqüentes perdas destes pelos processos erosivos (SILVA e POLITANO, 1995, PAULA, 1997, BRANDINI, 2000). Como conseqüência a erosão hídrica está assoreando os reservatórios de Ilha Solteira e Três Irmãos, portanto, reduzindo a vida útil dessas usinas hidrelétricas (SILVA e POLITANO, 1995). Visto que a ocupação antrópica para a instalação de pastagens devastou a vegetação natural, observa-se na área de estudo, uma distribuição descontínua e dentro de índices inexpressivos das fitofisionomias mata cerrado e capoeira (SILVA, 1991).

A análise da distribuição espacial dos usos antrópicos na paisagem do município de Ilha Solteira revelou escassez de áreas naturais, em relação às áreas antrópicas, em que o tipo de espaço dominante é constituído pelos sistemas agrários. As áreas naturais constituíram-se em fragmentos remanescentes, com tamanhos reduzidos e isolados entre si, agravando o problema de perda de biodiversidade nesses sistemas (FREITAS LIMA, 1997). Esse mesmo autor citou que a maioria dos córregos no município de Ilha Solteira, encontra-se totalmente desprovida de mata ciliar ou representada apenas por fragmentos, muitos dos quais de tamanho reduzido.

Estudos realizados na microbacia hidrográfica do Córrego do Ipê demonstraram que apenas $13 \%$ das propriedades agrícolas possuem áreas remanescentes de vegetação marginal com o agravante de que estes fragmentos estão ficando cada vez menores e raros. (POLETO, 2003). Considerando-se que as matas ciliares têm grande importância no equilíbrio dos ecossistemas aquáticos, a destruição da mata ciliar pela degradação da zona ripária pode, a médio e longo prazos, diminuir a capacidade de armazenamento da microbacia e conseqüentemente a vazão na estação seca (LIMA e ZAKIA, 2000).

O objetivo deste trabalho foi avaliar, por meio do Índice de Qualidade da Água (IQA), a qualidade da água da microbacia hidrográfica (MH) do Córrego do Ipê, inserida nos limites do município de Ilha Solteira (SP) e o seu estado de degradação associado à utilização da área de entorno.

\section{MATERIAL E MÉTODOS}

\subsection{Caracterização da área de estudo}

O município de Ilha Solteira está localizado na região Noroeste do Estado de São Paulo, aproximadamente a $653 \mathrm{~km}$ de São Paulo, via rodovia Feliciano Sales da Cunha e via Anhanguera. Está situado na Província Geomorfológica do Planalto Ocidental, região das "zonas indivisas" (IPT, 1981). O clima da região em que se encontra o município de Ilha Solteira é quente e úmido, do tipo Aw, segundo a classificação de Koppen (CARDOSO, 1980). De acordo com dados da Estação Meteorológica de Ilha Solteira, a temperatura média anual é de $24,1^{\circ} \mathrm{C}$ e a umidade relativa do ar média anual é de 70,8\% (HESPANHOL, 1996). A precipitação 
pluviométrica anual varia de $1.100 \mathrm{~mm}$ a $1.300 \mathrm{~mm}$, com uma estação seca entre os meses de maio e setembro/outubro. O regime climático é controlado por quatro massas de ar: massa equatorial continental quente, massa tropical continental quente e seca, massa tropical atlântica e massa de ar polar, do Atlântico Sul (CINDIRU apud FREITAS LIMA, 1997).

Segundo o Instituto Brasileiro de Geografia e Estatística (IBGE, 2002), a população de Ilha Solteira foi estimada em 23.996 habitantes. O uso antrópico predominante na paisagem do município é caracterizado pelas pastagens (67\%). A vegetação, representada por fragmentos remanescentes da floresta latifoliada tropical, corresponde a apenas $1 \%$ da área do município (FREITAS LIMA, 2003). Além da pastagem, as áreas de estudo apresentam cultivos agrícolas anuais e perenes, em menor proporção.

Os municípios limítrofes de Ilha Solteira são os seguintes: ao Norte, Rubinéia; ao Sul, Itapura; ao Oeste, Rio Paraná e Selvíria - MS; ao Leste, Pereira Barreto.

A área de estudo é a MH do Córrego do Ipê que está inserida no município de Ilha Solteira, entre as seguintes coordenadas geográficas: Latitude $20^{\circ} 16^{\prime} 00^{\prime \prime}$ a

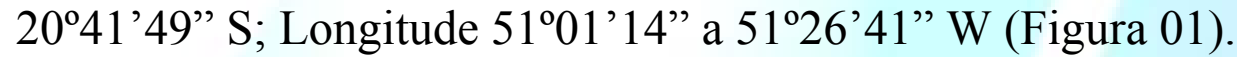

Mediante estudos das cartas topográficas, constatou-se que a $\mathrm{MH}$ do Córrego do Ipê possui área aproximada de $23 \mathrm{~km}^{2}$, perímetro de $20 \mathrm{~km}$ e $90 \mathrm{~m}$ de declive em aproximadamente $4.500 \mathrm{~m}$.

\subsection{Pontos de Amostragem}

No presente trabalho, foram realizadas coletas quinzenais na $\mathrm{MH}$ do Córrego do Ipê, em três pontos pré-estabelecidos, indicados na Figura 02. As amostras foram preservadas de acordo com o Guia Técnico de Coleta de Amostras (CETESB, 1987) até a realização dos ensaios. Durante o período da pesquisa efetuaram-se estudos da utilização do solo e entrevistas com os moradores da microbacia aplicando-se um questionário, com questões abertas e de múltipla escolha para avaliar a relação da qualidade da água com possíveis lançamentos de poluentes na MH.

\subsection{Metodologias}

\subsubsection{Levantamento de campo}

As amostras foram coletadas quinzenalmente nos três pontos selecionados, no período de março a dezembro de 2002, visando incluir as diferenças climáticas da MH nas quatro estações do ano. 


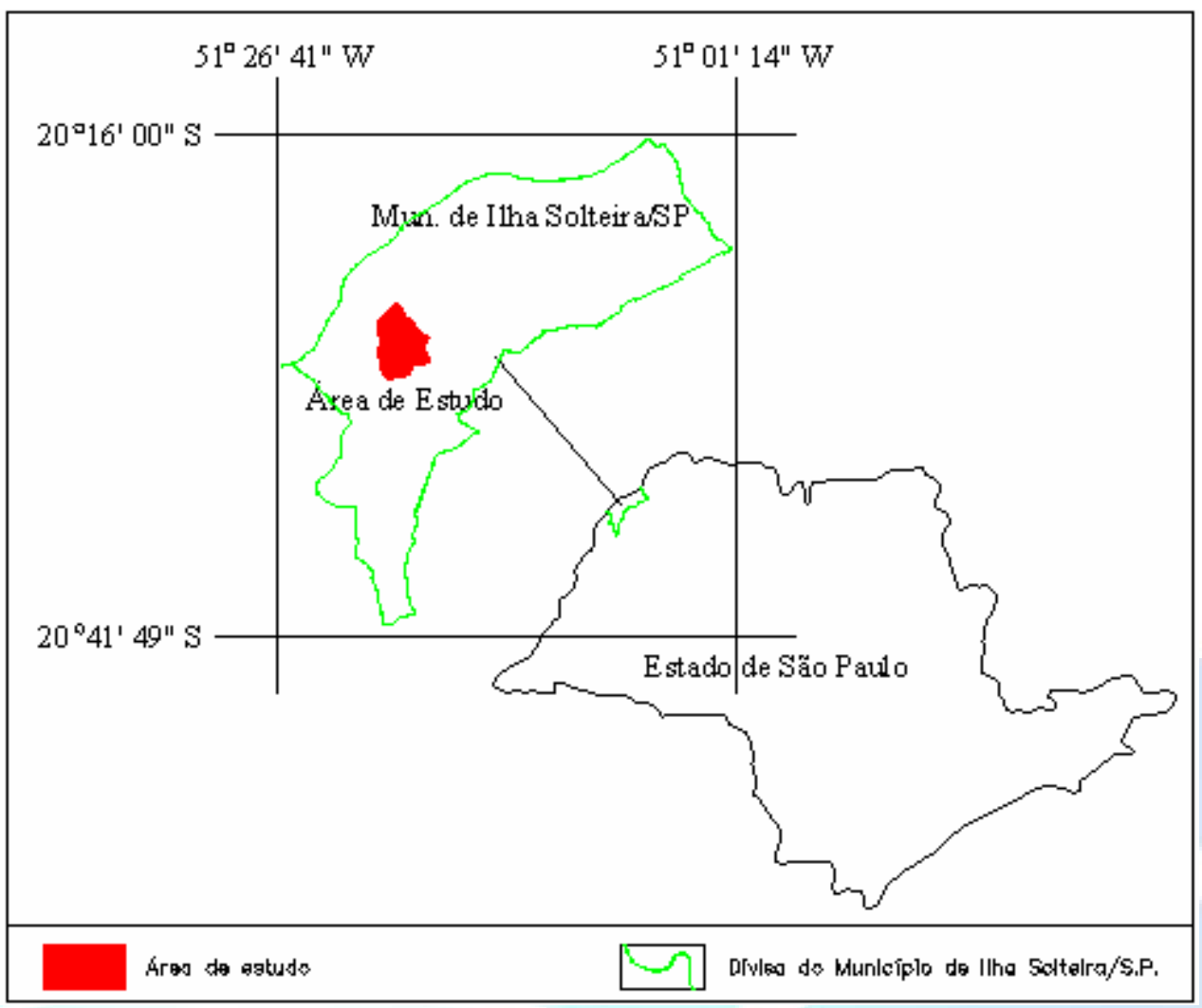

Figura 1. Localização da Microbacia Hidrográfica do Córrego do Ipê no Estado de São Paulo. Fonte: Adaptado de Porto (2002)

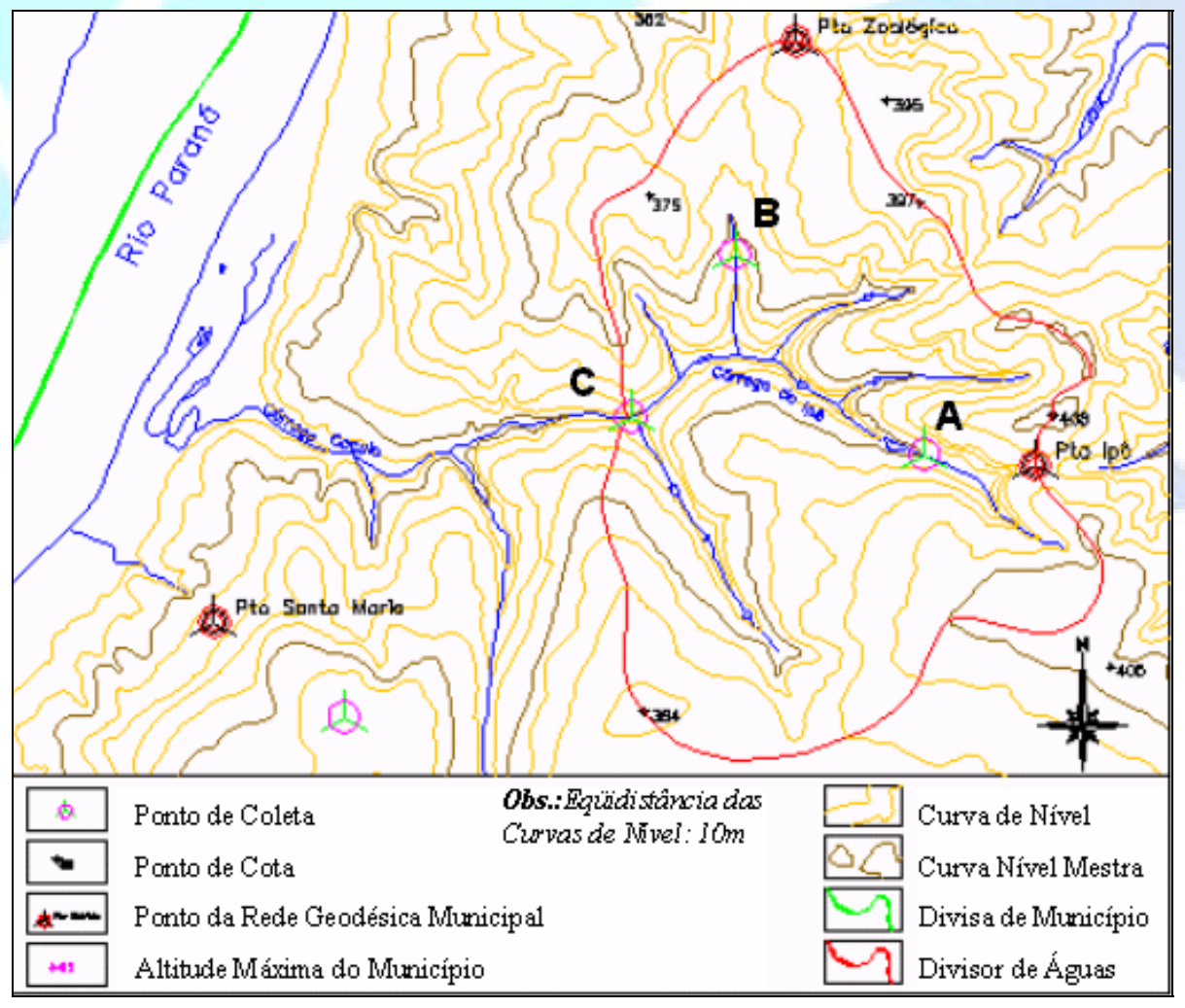

Figura 2. Mapa da microbacia hidrográfica do Córrego do Ipê com os três pontos de coleta de água. Fonte: Adaptado de Porto (2002) 
Os pontos de coleta são caracterizados de acordo com a Tabela 1.

Tabela 1 - Localização dos pontos de coleta, coordenadas e vazão para as amostragens realizadas, na M. H. do Córrego do Ipê em Ilha Solteira -SP.

\begin{tabular}{lccc}
\hline Localização/Elevação & \multicolumn{3}{c}{ Pontos de Coleta } \\
Coordenadas/Vazão & $\mathrm{A}$ & $\mathrm{B}$ & $\mathrm{C}$
\end{tabular}

Localização $\quad$ Bairro Ipê $\quad$ Jardim Aeroporto $\quad$ Trevo de Ilha Solteira

\begin{tabular}{llll}
\hline Elevação (m) & 351 & 343 & 308
\end{tabular}

\begin{tabular}{llll}
\hline Latitude & $20^{0} 27^{\prime} 09^{\prime} \mathrm{S}$ & $20^{0} 25^{`} 46,5^{\prime} \mathrm{S}$ & $20^{0} 26^{`} 55,9^{\prime \prime} \mathrm{S}$ \\
Longitude & $51^{0} 18^{`} 59^{\prime} \mathrm{W}$ & $51^{0} 20^{`} 06,8^{\prime \prime} \mathrm{W}$ & $51^{0} 20^{\prime} 41,8^{\prime} \mathrm{W}$
\end{tabular}

Vazão mínima

período de seca $\left(\mathrm{m}^{3} / \mathrm{s}\right) \quad 0,0149 \quad 0,0024 \quad 0,0889$

Vazão máxima

período de chuvas $\left(\mathrm{m}^{3} / \mathrm{s}\right) \quad 0,0202 \quad 0,0043 \quad 0,135$

Foram tomadas mensalmente medidas da vazão nos três pontos de coleta. No ponto "A" e "C" utilizou-se o Método do Flutuador (AZEVEDO NETTO, 2000). No ponto "B" e comparativamente no ponto " $A$ " foram feitas medições com medidores do tipo Parshall de $\mathrm{w}=6$. No ponto "C" também se utilizou o programa SIGRH Sistema Integrado de Gerenciamento de Recursos Hídricos do Estado de São Paulo.

Efetuou-se verificações de possíveis extravasamentos nas bombas de recalque de esgoto, operadas pela prefeitura municipal de Ilha Solteira e visitas ao pátio de manutenção da mesma. Foram realizadas análises descritivas das tendências e oscilações de cada variável por período sazonal, estudando-se ainda as hipóteses de verificação do enquadramento aos limites estabelecidos pela Resolução $n^{\circ}$ CONAMA 357/2005 para um rio de Classe 2. (BRASIL, 2005).

Utilizou-se o Índice de Qualidade da Água (IQA) da CETESB, para classificação da água para abastecimento (CETESB, 2002, 2004). O IQA foi calculado para todas as coletas comparando-se os resultados encontrados com os índices pluviométricos de cada mês e as possíveis fontes de poluição.

\subsubsection{Variáveis Analisadas}

O Quadro 2 contém as variáveis avaliadas, os métodos adotados e as especificações dos equipamentos utilizados nas análises, as quais foram baseadas no 
APHA (1998) - Standard Methods for Examination of Water and Wastewater, e pela metodologia de espectrofotometria da Hach.

$\mathrm{Na}$ última coleta analisou-se a quantidade em mg. $\mathrm{L}^{-1}$, de amônia $\left(\mathrm{NH}_{3}\right)$ e de nitrato $\left(\mathrm{NO}_{3}\right)$, procurando avaliar a localização dos três pontos dentro das zonas de autodepuração. As análises laboratoriais da água coletada foram agrupadas como apresentado a seguir:

- Parâmetros físicos: $\mathrm{pH}$, Turbidez (NTU), Cor $(\mathrm{uH})$, e Temperatura $\left({ }^{\circ} \mathrm{C}\right)$;

- Parâmetros químicos: Nitrogênio Total $\left(\mathrm{mg} . \mathrm{L}^{-1}\right)$, Fósforo Total $\left(\mathrm{mg} . \mathrm{L}^{-1}\right)$, Ferro (mg. $\left.\mathrm{L}^{-1}\right)$, Demanda Bioquímica de Oxigênio - DBO (mg. $\left.\mathrm{L}^{-1}\right)$, Demanda Química de Oxigênio - DQO $\left(\mathrm{mg}^{-\mathrm{L}^{-1}}\right)$, Oxigênio Dissolvido OD (mg. $\left.\mathrm{L}^{-1}\right)$, Sólidos Suspensos (mg. $\left.\mathrm{L}^{-1}\right)$, Sólidos Dissolvidos $\left(\mathrm{mg} . \mathrm{L}^{-1}\right)$, Sólidos Totais $\left(\mathrm{mg} . \mathrm{L}^{-1}\right)$;

- Parâmetros biológicos: Coliformes Totais (NMP/100mL) e Coliformes Fecais $(\mathrm{NMP} / 100 \mathrm{~mL})$.

Os dados coletados foram tratados em planilhas eletrônicas de cálculo para geração de gráficos e figuras auxiliares na avaliação da qualidade da água e submetidos à análise estatística usual.

$\mathrm{Na}$ construção da fórmula paramétrica para calcular o IQA, foram estabelecidas curvas de variação da qualidade das águas de acordo com o estado ou a condição de cada um dos 09 parâmetros contemplados, assegurando adequado grau de precisão mediante o uso individual ou combinado de funções lineares e não lineares segmentadas em faixas de consideração.

Quadro 1 - Métodos e especificações dos equipamentos empregados para análises físico-químicas e microbiológicas e limites de detecção. Parâmetros analisados nas amostras coletadas na $\mathrm{MH}$ do Córrego do Ipê.

\begin{tabular}{|l|l|c|l|}
\hline \multicolumn{1}{|c|}{ Parâmetros } & \multicolumn{1}{|c|}{ Método } & $\begin{array}{c}\text { Limite } \\
\text { de } \\
\text { Detecção }\end{array}$ & \multicolumn{1}{|c|}{$\begin{array}{c}\text { Equipamentos } \\
\text { e Materiais }\end{array}$} \\
\hline Turbidez (NTU) & Nefelométrico & 0,01 & Turbidímetro/Hach/2100AN v1.2 \\
\hline Cor (uH) & Espectrofotométrico & 1 & $\begin{array}{l}\text { Espectrofotômetro Odyssey/ } \\
\text { Hach/DR-2500 }\end{array}$ \\
\hline Temperatura da água $\left({ }^{\circ} \mathrm{C}\right)$ & Eletrométrico & 0,1 & $\begin{array}{l}\text { pHmetro de membrana/Hanna/ } \\
\text { HI8314 }\end{array}$ \\
\hline $\mathrm{pH}$ & Eletrométrico & 0,01 & $\begin{array}{l}\text { pHmetro de membrana/Hanna/ } \\
\text { HI8314 }\end{array}$ \\
\hline Nitrogênio Total $\left(\mathrm{mg} . \mathrm{L}^{-1}\right)$ & $\begin{array}{l}\text { Digestão por Persulfato e } \\
\text { Espectrofotométrico }\end{array}$ & 0,1 & $\begin{array}{l}\text { 1. COD Reactor/ Hach } \\
\text { 2. Espectrofotômetro Odyssey/ } \\
\text { Hach/DR-2500 }\end{array}$ \\
\hline Fósforo Total $\left(\mathrm{mg} \cdot \mathrm{L}^{-1}\right)$ & $\begin{array}{l}\text { PhosVer 3, } \\
\text { Digestão por Ácido } \\
\text { Persulfato e }\end{array}$ & 0,01 & $\begin{array}{l}\text { 1. COD Reactor/ Hach } \\
\text { 2. Espectrofotômetro Odyssey/ } \\
\text { Hach/DR-2500 }\end{array}$ \\
\hline
\end{tabular}




\begin{tabular}{|c|c|c|c|}
\hline & Espectrofotométrico & & \\
\hline Ferro (mg.L L $^{-1}$ ) & Colorimétrico & 0,1 & Microquant/Merck \\
\hline $\mathrm{OD}\left(\mathrm{mg} \cdot \mathrm{L}^{-1}\right)$ & $\begin{array}{l}\text { Método de Winkler } \\
\text { Modificado }\end{array}$ & 0,1 & Titulador \\
\hline DBO & $\begin{array}{l}\text { Método das Diluições, } \\
\text { Incubado a } 20^{\circ} \mathrm{C}, 5 \text { dias }\end{array}$ & 0,1 & Titulador \\
\hline$\overline{\mathrm{DQO}}\left(\mathrm{mg} \cdot \mathrm{L}^{-1}\right)$ & $\begin{array}{l}\text { Disgetão por reator, } \\
\text { Espectrofotométrico }\end{array}$ & 1,0 & $\begin{array}{l}\text { 1. COD Reactor/ Hach } \\
\text { 2. Espectrofotômetro Odyssey/ } \\
\text { Hach/DR-2500 }\end{array}$ \\
\hline $\begin{array}{l}\text { Sólidos Totais, } \\
\text { Sólidos Dissolvidos e } \\
\text { Sólidos Suspensos } \\
\left(\mathrm{mg} . \mathrm{L}^{-1}\right)\end{array}$ & Gravimétrico & 1,0 & $\begin{array}{l}\text { 1. Cápsula de Porcelana } \\
\text { 2. Disco de microfibra de vidro/ } \\
\text { Sartorius } \\
\text { 3. Balança eletrônica de precisão } \\
\text { de } 0,1 \mu \mathrm{g} / \text { Bel Mark/ } \\
\mathrm{U} 210 \mathrm{~A} \\
\text { 3. Estufa/Marconi/MA033/ } \\
\text { temp. } 120^{\circ} \mathrm{C} \\
\text { 4. Dissecador/Pyrex/200mm }\end{array}$ \\
\hline $\begin{array}{l}\text { Coliformes Totais e Fecais } \\
(\mathrm{NMP} / 100 \mathrm{~mL})\end{array}$ & $\begin{array}{l}\text { Contagem de Escherichia } \\
\text { coli }\end{array}$ & 1,0 & $\begin{array}{l}\text { 1. Placas Petrifilm/3M } \\
\text { 2. Estufa de cultura/Fanem/ } \\
\text { A-LT } 502\end{array}$ \\
\hline
\end{tabular}

O IQA é calculado a partir das curvas de variação sintetizadas em um conjunto de curvas médias para cada parâmetro, bem como seu peso relativo correspondente (BOLLMANN e MARQUES, 2000). Ou seja, o IQA é o resultado ponderado das qualidades de água correspondentes aos parâmetros: temperatura da amostra, $\mathrm{pH}$, oxigênio dissolvido, demanda bioquímica de oxigênio $\left(5\right.$ dias, $\left.20^{\circ} \mathrm{C}\right)$, coliformes termotolerantes, nitrogênio total, fósforo total, sólidos totais e turbidez.

$$
\mathrm{IQA}=\prod_{\mathrm{i}=1}^{\mathrm{n}} \mathrm{q}_{\mathrm{i}}^{\mathrm{w}_{\mathrm{i}}}
$$

onde:

IQA: Índice de Qualidade das Águas;

qi : qualidade do i-ésimo parâmetro, um número entre 0 e 100, obtido da respectiva "curva média de variação de qualidade", em função de sua concentração ou medida e;

wi : peso correspondente ao i-ésimo parâmetro, um número entre 0 e 1 , atribuído em função da sua importância para a conformação global de qualidade, sendo que:

$$
\sum_{i=1}^{n} w_{i}=1
$$

em que:

n: número de parâmetros que entram no cálculo do IQA. 
No caso de não se dispor do valor de algum dos 9 parâmetros, o cálculo do IQA é inviabilizado.

A partir do cálculo efetuado, pode-se determinar a qualidade das águas brutas indicada pelo IQA numa escala de 0 a 100 (Tabela 02).

Tabela 2 - Escala de qualidade da água indicada pelo IQA. Fonte: CETESB, 2004

\begin{tabular}{|c|c|}
\hline GRADUAÇÃO & QUALIDADE \\
\hline $79<$ IQA $\leq 100$ & Qualidade ótima \\
\hline $51<$ IQA $\leq 79$ & Qualidade boa \\
\hline $36<$ IQA $\leq 51$ & Qualidade aceitável \\
\hline $19<$ IQA $\leq 36$ & Qualidade ruim \\
\hline IQA $\leq 19$ & Qualidade péssima \\
\hline
\end{tabular}

\section{RESULTADOS E DISCUSSÃO}

\subsection{Ponto "A"}

A Figura 3 insere os valores do IQA calculados para o Ponto "A", onde se pode observar que os valores oscilaram sazonalmente, piorando a qualidade nos dias chuvosos com o aumento nas concentrações de sólidos. As variáveis que mais influenciaram negativamente o IQA neste ponto foram sólidos totais, coliformes fecais, DBO e fósforo. Os valores de IQA para este ponto variaram de 31,8 a 59,3. A média de 47,9 classifica a água como aceitável.

\subsection{Ponto "B"}

Na Figura 4, estão incluídos os dados do Ponto "B" que indicam os resultados de menor IQA. Os valores oscilaram sazonalmente de forma irregular, com alguns períodos de melhora em dias chuvosos causados pela diluição de alguns poluentes; este ponto também não apresentou aumento nas concentrações de sólidos no período chuvoso analisado. As variáveis que mais contribuíram para agravar os valores do IQA foram coliformes fecais, DBO e fósforo. Os valores de IQA para este ponto variaram de 17,5 a 35,4 com média de 23,8, o que classifica a água como ruim. 


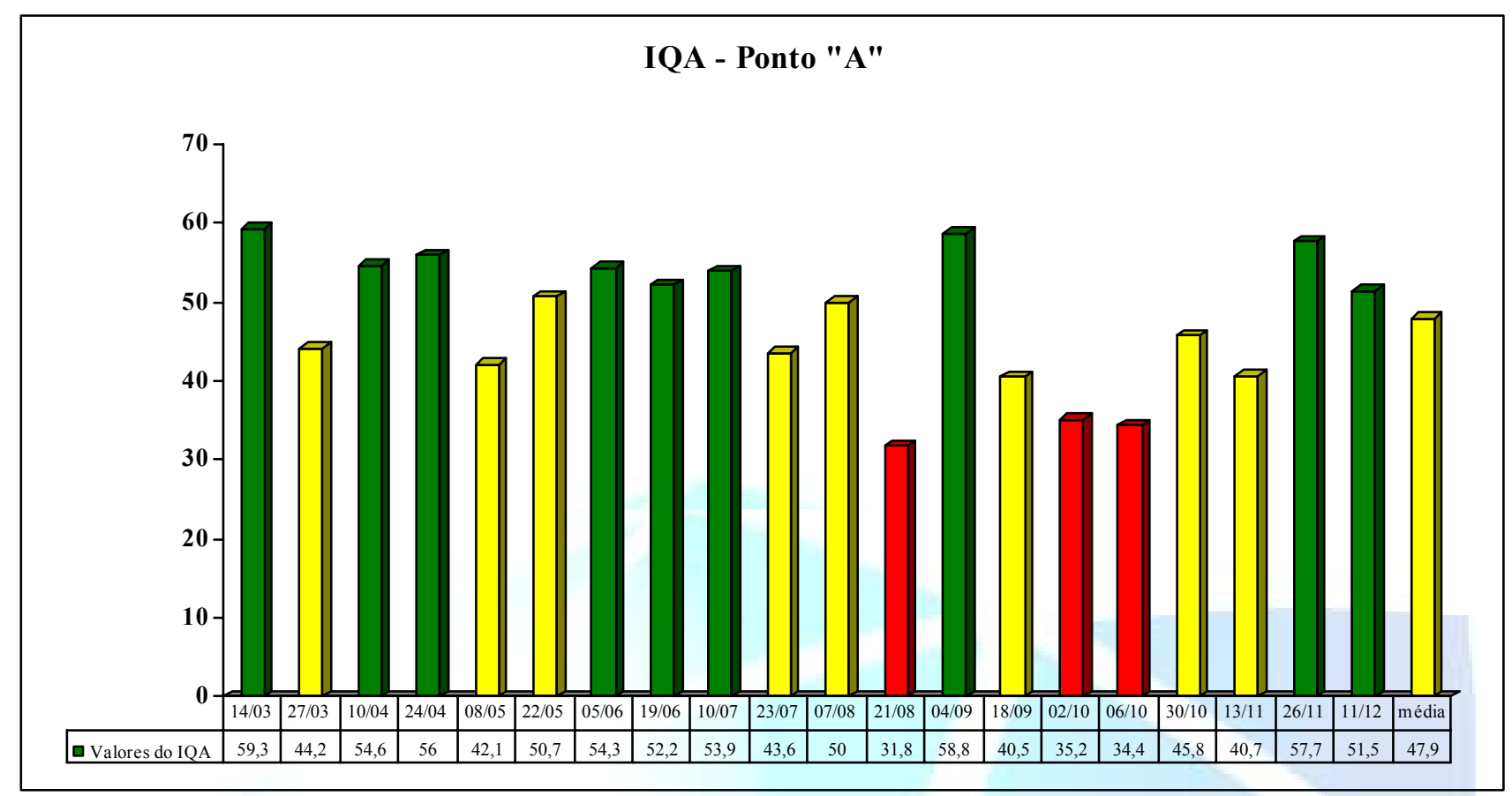

Figura 3. IQA do Ponto "A", no período de março a dezembro de 2002, localizado na Microbacia Hidrográfica do Córrego do Ipê, Ilha Solteira - SP

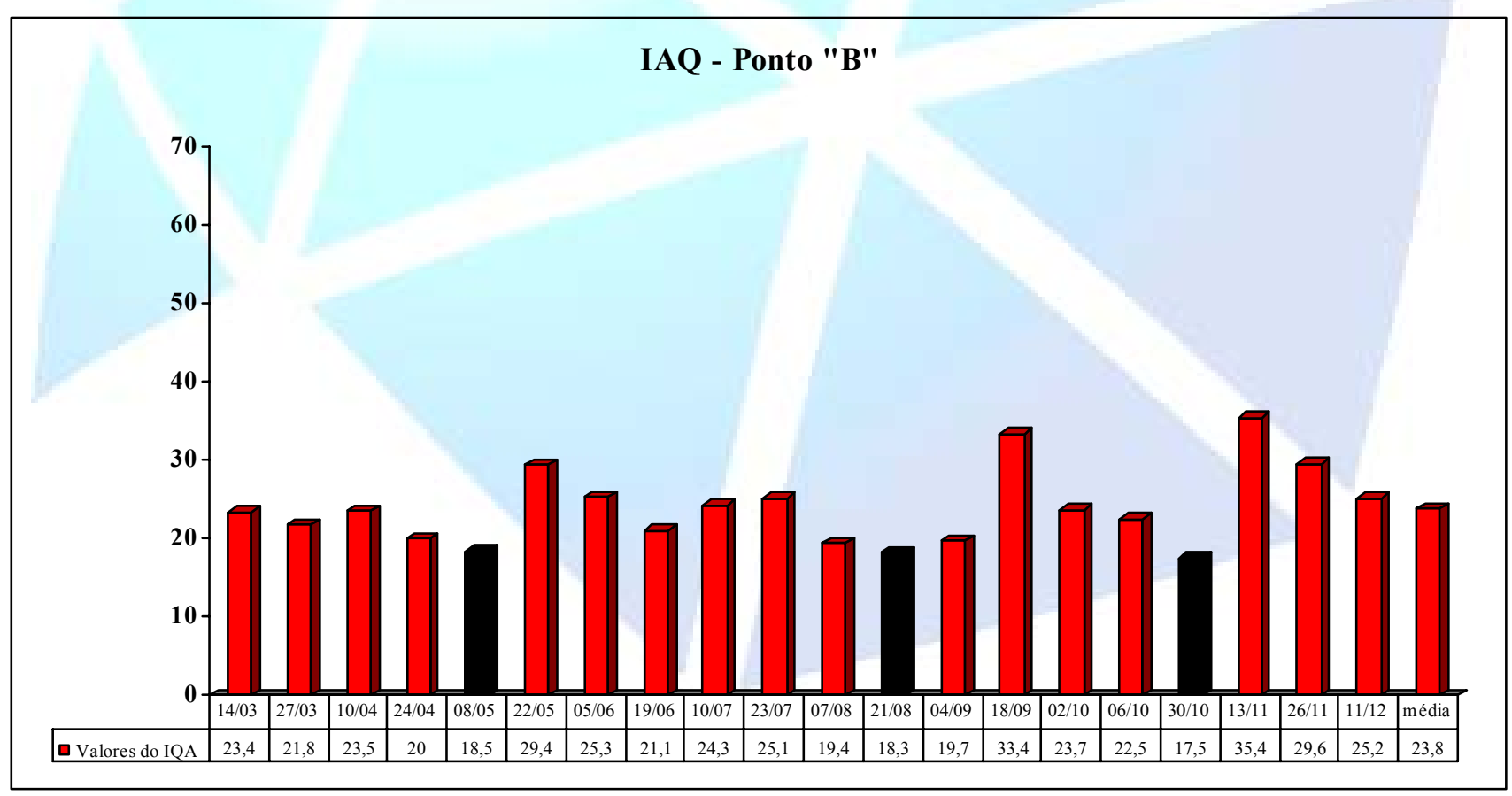

Figura 4. IQA do Ponto "B", no período de março a dezembro de 2002, localizado na Microbacia Hidrográfica do Córrego do Ipê, Ilha Solteira - SP 


\subsection{Ponto "C"}

Os resultados dos cálculos do IQA para o Ponto "C" podem ser visualizados na Figura 5. Este índice ao longo do período sofreu influências das variações sazonais, indicando melhor qualidade de água no período de seca, devido à redução do carreamento de matéria orgânica para o corpo de água. As maiores influências sobre os valores obtidos ficaram a cargo dos parâmetros: coliformes fecais, turbidez e sólidos totais. Os valores de IQA para o Ponto "C" variaram de 32,0 a 66,5. O valor médio de 53,3 para esse ponto classifica a água como de boa qualidade.

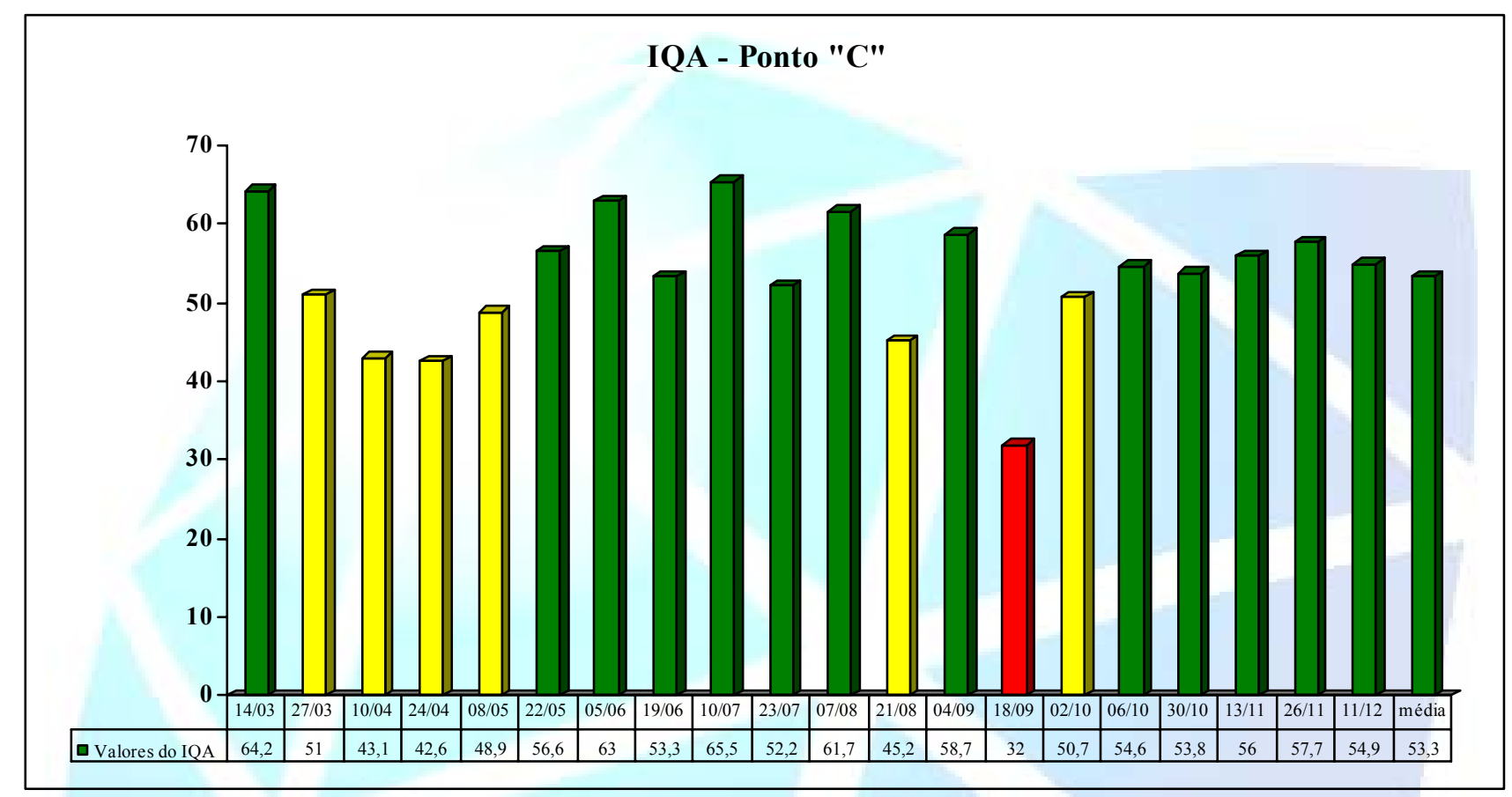

Figura 5. IQA do Ponto "C", no período de março a dezembro de 2002, localizado na Microbacia Hidrográfica do Córrego do Ipê, Ilha Solteira - SP

De forma geral constata-se que o Ponto "B" é o que apresenta pior qualidade de água, em relação aos demais pontos, com base no IQA, sendo que em três amostragens a qualidade da água foi considerada péssima. Em nenhuma amostragem, mesmo nos períodos chuvosos a qualidade da água foi classificada sequer como regular. Este fato está muito provavelmente relacionado ao maior percentual de urbanização neste ponto, associado à ausência quase total de vegetação. O Ponto "A" ficou em posição intermediária em termos de qualidade da água em relação aos demais pontos, porque embora receba fontes difusas e pontuais de poluição, oriundas da zona rural está localizado a montante da área urbanizada. O Ponto "C", localizado à jusante da área urbanizada, provavelmente por estar mais distante desta, foi o que apresentou melhor IQA, embora em várias amostragens a qualidade da água tenha se mostrado apenas aceitável ou ruim. Os valores dos índices de IQA definidos neste estudo reafirmaram a degradação do córrego em todo o seu percurso, com pontos mais degradados onde a influência antrópica se mostrou mais acentuada. 
Estudos realizados na microbacia do Córrego do Ipê (POLETO e CARVALHO, 2004) indicaram o seu estado de degradação, com avançado estado de assoreamento em praticamente toda sua extensão devido à pequena quantidade de matas ciliares e ao mau uso do solo. A qualidade da água pode alterar-se negativamente na época das chuvas com o aumento nas concentrações de alguns parâmetros, como por exemplo, turbidez, fósforo e sólidos totais de acordo com pesquisas realizadas no Córrego Campestre em Lins - SP, onde o IQA variou de 10,3 (qualidade péssima da água) à 64,5 (qualidade boa) (CUELBAS, 2006). Investigações similares realizadas na microbacia do Córrego Gavanhery em Getulina - SP indicaram valores de IQA variando de 33,5 (ruim) a 60,0 (boa), sendo constatada a poluição do curso de água por efluentes rurais e urbanos, associada com o mau uso do solo e a pequena quantidade de matas ciliares (RODRIGUES JÚNIOR, 2008), Esta situação acarreta o incremento das cargas de sólidos trazidas pelo deflúvio superficial, causando turbidez à água. Esta é atribuída a partículas sólidas em suspensão, e pode ser provocada por plâncton, detritos orgânicos e outras substâncias como zinco, ferro, composto de manganês e areia, resultantes do processo natural de erosão, ou adição de despejos domésticos ou industriais (BATALHA e PARLATORE, 1977).

Ressalta-se que com o aumento da matéria em suspensão ocorre a intensificação do grau de poluição e a diminuição da penetração da luz, o que prejudica a fotossíntese e reduz a reposição de oxigênio (BRANCO, 1983). Constatando-se que valores mais altos de turbidez e sólidos foram registrados na época das chuvas, pode - se associar esses resultados ao processo natural de erosão, ao uso inadequado do solo e a falta de uma vegetação ciliar suficientemente capaz de reter parte dessas cargas. Esses fatores podem ser considerados como os principais causadores das alterações na qualidade da água na microbacia nessa época do ano.

É importante ressaltar que, a qualidade da água, obtida através do IQA, apresenta algumas limitações, entre elas a de considerar apenas a sua utilização para o abastecimento público (BASSO e CARVALHO, 2007). Além disso, mesmo considerando-se esse fim específico, o índice não contempla outros parâmetros, tais como: metais pesados, compostos orgânicos com potencial mutagênico, substâncias que afetam as propriedades organolépticas da água e o potencial de formação de trihalometanos das águas de um manancial. (CETESB, 2002).

\section{CONCLUSÕES}

1. Com base nos resultados obtidos nos testes de IQA e visitas "in loco", constatou-se um avançado estágio de degradação do Córrego do Ipê, manifestado pela inexistência de mata ciliar, assoreamento, elevação dos teores de elementos fertilizantes (fósforo e nitrogênio) e aumento dos níveis de concentrações de coliformes fecais e totais em alguns pontos analisados, com 
características físico-químicas e bacteriológicas similares a um esgoto típico de fraca concentração.

2. A degradação da microbacia ocorreu entre outros fatores ao processo de urbanização que resultou na contaminação do Córrego do Ipê, com acentuado comprometimento da qualidade de suas águas, decorrente de fontes pontuais e difusas que são resultado tanto dos esgotos clandestinos lançados diretamente nesse corpo de água quanto da falta de práticas eficientes de conservação do solo e de retenção das águas pluviais e controle de erosões. As fontes difusas foram observadas nas áreas menos urbanizadas, onde predominam chácaras que têm suas atividades ligadas à criação de animais suínos, aves e bovinos, e a atividade de horticultura.

3. Os valores obtidos para a qualidade da água são inferiores aos de um rio de Classe II, com destaque para o Ponto "B", situado no meio urbano, que obteve os piores resultados, com classificação variando de ruim a péssima.

4. Há indícios de falta de consciência e percepção ambiental dos ribeirinhos os quais negligenciam a utilidade e a necessidade de se preservar o riacho, vendo nele um empecilho à sua qualidade de vida, o que remete para a necessidade de uma combinação de política de recursos hídricos, educação ambiental, planejamento e aplicabilidade das leis para reduzir a degradação e possibilitar uma maior proteção do meio ambiente.

\section{AGRADECIMENTOS}

À Fundação para o Desenvolvimento da UNESP- FUNDUNESP, pelo auxílio concedido para a realização desta pesquisa.

Ao Prof. Dr. Tsunao Matsumoto do Departamento de Engenharia Civil da Faculdade de Engenharia de Ilha Solteira - UNESP, pela utilização do Laboratório de Saneamento.

\section{REFERÊNCIAS}

APHA - AMERICAN PUBLIC HEALTH ASSOCIATION. Standard Methods for the Examination of Water and Wastewater. 20th Edition Washington: American Public Health Association, AWWA, WPCF, 1998. 1569p.

AZEVEDO NETTO, J.M. Manual de hidráulica. 8.ed. São Paulo: Edgard Blücher, 2000. p. 669-670. 
BASSO, E.R., CARVALHO, S.L.Avaliação da Qualidade da Água em duas represas e uma lagoa no município de Ilha Solteira - S.P. Holos Environment, v.7 n.1, p.1629, 2007.

BATALHA, B.L.; PARLATORE, A. C. Controle da Qualidade da Água para o consumo Humano: Bases conceituais e operacionais. São Paulo: CETESB, 1977. $198 \mathrm{p}$.

BOLLMANN, H.A.; MARQUES, D. M. Bases para a estruturação de indicadores de qualidade de águas. RBRH - Revista Brasileira de Recursos Hídricos, São Paulo, v.5, n.1, p.37-60, 2000.

BRANDINI, O.L. Tipologia e distribuição dos processos erosivos do Município de Suzanápolis, SP. Três Lagoas. 2000. 40 f. Monografia (Trabalho de Graduação) Faculdade de Geografia, Universidade Federal do Mato Grosso do Sul. 2000.

BRANCO, S.M. Hidrobiologia Aplicada à Engenharia Sanitária. 2. ed. São Paulo: Editora CETESB, 1983.

BRASIL. Ministério do Meio Ambiente. Conselho Nacional do Meio Ambiente. Resoluções do CONAMA de n. ${ }^{\circ}$ 357, 5. ed. Brasília, DF. SEMA, 2005. 23 p.

CARDOSO, J.D. Bacia de acumulação de Ilha Solteira: estudos agroeconômicos visando à fixação de preços básicos para fins de desapropriação. São Paulo: CESP, 1980.

CETESB - COMPANHIA ESTADUAL DE TECNOLOGIA DE SANEAMENTO BÁSICO. Guia de Coleta e Preservação de Amostras de Água, CETESB, São Paulo, $1^{\circ}$ ed. 1987, 155p.

CETESB - COMPANHIA ESTADUAL DE TECNOLOGIA DE SANEAMENTO BÁSICO. Relatório da qualidade das águas interiores do Estado de São Paulo 2001. São Paulo: CETESB, 2002. 264 p.

CETESB - COMPANHIA ESTADUAL DE TECNOLOGIA DE SANEAMENTO BÁSICO. Relatório da qualidade das águas interiores do Estado de São Paulo 2003. São Paulo: CETESB, 2004. 264 p.

CUELBAS, L.P. Monitoramento e Avaliação da Qualidade da Água da Microbacia Hidrográfica do Córrego Campestre no Município de Lins, SP. 2007.118 f. Dissertação (Mestrado. em Engenharia Civil) Faculdade de Engenharia de Ilha Solteira, Universidade Estadual Paulista. 
FREITAS LIMA, E.A.C. Estudo da paisagem do Município de Ilha Solteira (SP): subsídios para o planejamento físico-ambiental. São Carlos, 1997. 107 f. Tese (Doutorado em Ciências Ambientais) - Universidade Federal de São Carlos, São Carlos, 1997.

FREITAS LIMA, E.A.C. Análise ambiental no Município de Ilha Solteira (SP): riscos ambientais associados com os usos atuais da terra. Ilha Solteira: UNESP/FEIS, 2003. p. 22-23. (Relatório FUNDUNESP, Processo 00002/02-DFP).

HESPANHOL, A.N. Dinâmica agro-industrial, intervenção estatal e a questão do desenvolvimento da região de Andradina (SP). Rio Claro, 1996. 273 f. Tese (Doutorado em Geografia) - Instituto de Geociências e Ciências Exatas, Universidade Estadual Paulista, 1996.

IBGE - INSTITUTO BRASILEIRO DE GEOGRAFIA E ESTATÍSTICA. Estudos e pesquisas 2: indicadores de desenvolvimento sustentável. Rio de Janeiro: IBGE, 2002. p. 115-120.

IPT - INSTITUTO DE PESQUISAS TECNOLÓGICAS. Mapa geomorfológico do Estado de São Paulo. São Paulo: IPT, 1981. p. 94.

LIMA, W.P.; ZAKIA, M.J.B. Hidrologia de Matas Ciliares. In: RODRIGUES, R. R.; LEITÃO FILHO, H.F. (Eds.) Matas Ciliares: Conservação e Recuperação. São Paulo: Ed. da Universidade de São Paulo, p. 33-44, 2000.

MEYBECK, M.; HELMER R. An introduction to water quality In: CHAPMAN, D. Water quality assessment. Cambridge, University Press, 1992. 585p.

PAULA, R.C. Avaliação dos principais fatores do meio físico do Município de Suzanápolis, SP, relacionados com a produção agropecuária mediante o emprego de imagens aéreas. Ilha Solteira: UNESP. 1997. 47 f. (Trabalho de Graduação em Agronomia) - Faculdade de Engenharia de Ilha Solteira, Universidade Estadual Paulista. 1997.

POLETO, C. Monitoramento e Avaliação de uma Microbacia Hidrográfica no Município de Ilha Solteira (SP), Ilha Solteira - SP, 2003. 161 f. Dissertação (Mestrado. em Engenharia Civil) Faculdade de Engenharia de Ilha Solteira, Universidade Estadual Paulista. 2003.

POLETO, C; CARVALHO, S.L. Problemas de degradação ambiental em uma microbacia hidrográfica situada no município de Ilha Solteira - SP, Brasil e sua percepção pelos proprietários rurais. Holos Environment, v.4 n.1, p.68-80, 2004. 
PORTO, O.S. Cartas Temáticas Digitais do Município de Ilha Solteira/SP para Auxílio à Gestão Territorial. Monografia de Bacharelado. Três Lagoas:

UFMS/CEUL, 2002.

PROJETO ÁGUAS E MINAS. Disponível em: http://www.aguaseminas.com.br. Acesso em: 05 mar. 2005.

RODRIGUES JR. F. Diagnóstico da Influência de Atividades Antrópicas na Qualidade da Água do Córrego Gavanhery no Município de Getulina - SP. 2008. 94 f. Dissertação (Mestrado em Engenharia Civil) Faculdade de Engenharia de Ilha Solteira, Universidade Estadual Paulista. 2008.

SILVA, H.R. Avaliação dos principais fatores do meio físico do Município de Pereira Barreto, SP, relacionado com a produção agropecuária, mediante o emprego de imagens aéreas. Ilha Solteira, 1991. 74 f. (Relatório do projeto de pesquisa apresentado para a Comissão Permanente de Regime de Trabalho com o fim de ser desenvolvido durante o período de estágio probatório). 1991.

SILVA, H.R.; POLITANO, W. Análise do uso e ocupação do solo e processos de erosão na área de influência do conjunto de Urubupungá: estudo dos municípios de Pereira Barreto, Ilha Solteira e Suzanápolis (SP). In: SIMPÓSIO NACIONAL DE CONTROLE DE EROSÃO, Bauru. Anais... Bauru: ABGE - IPT - DIGEO, v. 5, p.145-147, 1995.

TUNDISI, J.G. Água no século XX: enfrentando a escassez. 2.ed. São Carlos: Rima, 2003. 264 p. 